\title{
How well do genetic markers inform about responses to intraspecific admixture? A comparative analysis of microsatellites and RADseq
}

\section{Yeşerin Yıldırım}

Linnaeus University

Anders Forsman

Linnaeus University

Johanna Sunde ( $\nabla$ johanna.sunde@Inu.se )

Linnaeus University

\section{Research Article}

Keywords: Esox lucius, hybridization, interbreeding, microsatellites, offspring performance, outbreeding, pike, RADseq, SNP

Posted Date: March 1st, 2021

DOI: https://doi.org/10.21203/rs.3.rs-251722/v1

License: (c) (i) This work is licensed under a Creative Commons Attribution 4.0 International License. Read Full License 


\section{Abstract}

Background: Fitness consequences of intraspecific genetic admixture can vary from positive to negative depending on the genetic composition of the populations and environmental conditions. Because admixture has potential to influence the success of management and conservation efforts, genetic similarity has been suggested to be used as a proxy to predict the outcome. Studies utilizing microsatellites (a neutral marker) to investigate associations between genetic distance and admixture effects show conflicting results. Marker types that yield information on genome-wide and/or adaptive variation might be more useful for predicting responses to inter-population hybridization. In this study we utilized published data for three populations of pike (Esox lucius) to investigate associations between offspring performance (hatching success) and parental genetic similarity in experimentally purebred and admixed families, based on neutral (microsatellites), genome-wide neutral (RADseq SNPs), and adaptive (SNPs under selection) markers.

Results: Estimated similarity varied among the markers, likely reflecting differences in their inherent properties, but was consistently higher in purebred than admixed families. A significant interaction between marker type and admixture treatment reflected that neutral SNPs yielded higher estimates than adaptive SNPs for admixed families whereas no difference was found for purebred families, which indicates that neutral similarity was not reflective of adaptive similarity. When all samples were pooled, no association between similarity and performance was found for any marker. For microsatellites, similarity was positively correlated with hatching success in purebred families, whereas no association was found in admixed families; however, the direction of the effect differed between the population combinations.

Conclusions: The results strengthen the notion that, as of today, there is no proxy that can reliably predicted the outcome of admixture. This emphasizes the need of further studies to advance knowledge that can shed light on how to safeguard against negative consequences of admixture, and thereby inform management and promote conservation of biological diversity.

\section{Background}

Intraspecific genetic admixture (henceforth 'admixture') occurs when separated populations starts interbreeding [1]. It occurs naturally in many terrestrial and aquatic species in the wild as a consequence of dispersal [2], and can also occur as a result of anthropogenic activities, for example management actions to support populations (e.g. supplementations and translocations) [3, 4], removal of dispersal barriers [5], and escapes of farmed individuals [6].

Admixture affects the genetic composition of the involved populations and tends to increase the genetic variation in the receiving population. Increased genetic variation is generally considered to positively influence aspects of population performance. For example, it has been shown that genetically and phenotypically more diverse populations are better able to cope with environmental change, and to 
colonize novel environments [2, 7-10]. Admixture can also have positive fitness effects by allowing creation of novel gene combinations and dampening inbreeding depression by masking detrimental effects of deleterious recessive alleles (heterosis) [1,3]. However, the influx of new genetic material can also result in negative fitness effects. If the involved populations are highly differentiated, genomic incompatibilities might exist (e.g. as a result of chromosomal rearrangements in the parental populations) [11, 12], and admixture may thus lead to outbreeding depression. In addition, admixture between populations that have adapted to different environmental conditions might dilute favorable alleles [1], give rise to offspring with intermediate phenotypes that are not optimal in either of the parental environments $[4,13]$, and has potential to impair fitness in subsequent generations by breaking up coadapted gene complexes or by underdominance (i.e. heterozygote disadvantage) [1,4,13-15]. The net outcome (with regards to both magnitude and direction) of the response to admixture will be determined by an interplay between these mechanisms, and will thus depend on the genetic composition of the parental populations, local adaptations and environmental conditions [13].

The motivation for management and conservation efforts resulting in admixture is to increase productivity, viability, and adaptability of populations $[3,11,14]$. To avoid undesirable outcomes of such efforts, it would be valuable to have a reliable proxy that could be used to predict the response to admixture. Genetic similarity has been put forward as such a candidate proxy [11, 14]. However, empirical studies show conflicting results $[3,11,16-19]$, and further studies are therefore required to increase the understanding about potential associations between genetic similarity and the response to admixture, and to understand the reasons for the observed inconsistencies. Previous studies have commonly estimated genetic similarity based on a modest number (4-32) of microsatellite markers [20-23]. Microsatellites are mainly neutral markers that only occasionally reflect functional evolution, e.g. by residing within coding or regulatory regions or by being linked to functional loci $[24,25]$. Microsatellites have high mutation rates, and loci with relatively high allelic variation are commonly selected during the marker development $[26,27]$. As a consequence, genetic diversity estimates based on small numbers of microsatellites generally do not reflect the genome-wide diversity $[26,28]$. It is therefore possible that the inconsistencies in associations between genetic similarity and admixture effects in previous studies [3, $11,14,16,20,29]$ can be partly attributed to the use of non-representative estimates of genetic diversity, and estimates of genome-wide diversity might be better able to predict the outcome of admixture. In addition, estimates of parental genetic similarity might be more informative than population-based similarity, as the former accounts for the inter-individual variation [23].

The development of next generation sequencing techniques, such as Restriction-site associated DNA sequencing (RADseq) has enabled to genotype many markers at a low cost, even for non-model species [30]. RADseq commonly yields thousands of single nucleotide polymorphisms (SNPs), which provides better estimates of genome-wide diversity. It has also been shown that even relatively low numbers of SNPs $(\geq 50)$ generally has the same, if not more, statistical power compared to 20 microsatellites in relatedness studies [31], and that RADseq SNPs generally tend to outperform microsatellites in population genetic studies [32], but see [33]. In addition, it is functional - not neutral - genetic variation that is key for the evolvability of populations [34] with potential to influence the outcome of admixture. It 
can therefore be hypothesized that estimates of genetic similarity based on adaptive genetic variation (or divergence) offer a better predictor of the response to admixture [35]. RADseq SNPs thus offer a viable alternative as they can provide information on both neutral and adaptive genetic variation and differentiation.

The overall aim of the present study was to evaluate the potential of neutral (microsatellites), genomewide neutral (RADseq SNPs), and adaptive (outlier SNPs under selection) parental genetic similarity to predict admixture effects on offspring performance (hatching success) resulting from experimental matings of individuals representing genetically separated and locally adapted natural populations. To this end, we used previously published genetic and phenotypic data for three populations (Harfjärden, Lerviksbäcken, and Oknebäck; henceforth Harfjärden, Lervik and Okne) of anadromous Baltic Sea pike (Esox lucius) [32,36]. Pike is an ecologically and socio-economically important species that has suffered decreases during the last decades, and that has been the target of extensive management efforts [3740]. More specifically, we investigated whether: $I$ ) variation in parental similarity estimates among pairs of experimentally mated males and females were consistent or differed among the markers; ii) parental similarity was associated with offspring hatching success; and iii) the associations between parental similarity and offspring performance were consistent or depended on whether parental similarity was estimated based on neutral (microsatellites), genome-wide neutral (RADseq SNPs) or adaptive (RADseq SNPs under selection) genetic markers.

\section{Results}

\section{Comparison of parental similarity based on microsatellites and RADseq SNP data}

Estimates of pairwise parental similarity based on the three different datasets (microsatellites, neutral SNPs and adaptive SNPs) differed $\left(F_{2,178}=36.38, P<0.001\right.$, Fig. 1$)$, and differences were evident between all pairwise comparisons (Tukey's test: microsatellites - adaptive SNPs: $P=0.014$; microsatellites - neutral SNPs: $P<0.001$; adaptive SNPs - neutral SNPs: $P=0.003)$. Estimated parental similarity was highest for neutral SNPs (mean \pm SD: $0.55 \pm 0.07$ ), intermediate for adaptive SNPs (mean \pm SD: $0.49 \pm 0.15$ ), and lowest for microsatellites (mean \pm SD: $0.43 \pm 0.15$ ). In addition, the range of similarity estimates was smaller for neutral SNPs than for both microsatellites and adaptive SNPs (Fig. 1).

Figure 1 Estimates of pairwise parental similarity (proportion of alleles shared between individuals) for the same set of individuals $(N=64)$. Estimates are based on three different datasets: neutral (microsatellites), genome-wide neutral (RADseq SNPs), and adaptive (outlier RADseq SNPs under selection). Left panel show estimates for all families, and the right panel show estimates for the two admixture treatments (purebred and admixed) separated.

Parental similarity estimates were higher for purebred families than for admixed families for all three datasets (Student's t-test: microsatellites: $t=-5.88, \mathrm{df}=49.39, P<0.001$; neutral SNPs: $t=-9.63, \mathrm{df}=66.36$, 
$P<0.001$; adaptive SNPs: $t=-11.61, \mathrm{df}=72.61, P<0.001$ ) (Fig. 1 ). In addition, the analysis revealed a significant interaction effect between marker type and admixture treatment (purebred or admixed) $\left(F_{2,176}\right.$ $=10.16, P<0.001)$, which reflected that neutral SNPs yielded higher estimates for the admixed families than did microsatellites and adaptive SNPs (Tukey's test: microsatellites - adaptive SNPs: $P=0.15$; microsatellites - neutral SNPs: $P<0.001$; adaptive SNPs - neutral SNPs: $P<0.001)$, whilst there was no difference between neutral SNPs and adaptive SNPs for purebred families (Tukey's test: microsatellites adaptive SNPs: $P<0.001$; microsatellites - neutral SNPs: $P=0.008$; adaptive SNPs - neutral SNPs: $P=$ 0.70) (Fig. 1).

\section{No association between parental similarity and hatching success}

When all the samples were pooled, a large variation in hatching success was evident throughout the range of parental similarity for all three datasets (Fig. 2). Parental similarity was not associated with hatching success for any of the marker types (microsatellites: $F_{1,177}=1.23, P=0.27$, neutral SNPs: $F_{1,177}$ $=0.04, P=0.83$, adaptive SNPs: $F_{1,177}=0.27, P=0.61$ ).

When the samples were classified according to admixture treatment (purebred or admixed), to test whether associations between parental similarity and hatching success differed between purebred and admixed families, no significant interaction effect was found for either neutral SNPs (effect of treatment: $F_{1,176}=0.24, P=0.62$; effect of parental similarity: $F_{1,176}=0.045, P=0.85$; effect of interaction between parental similarity and admixture treatment: $F_{1,175}=0.67, P=0.41$ ) or adaptive SNPs (effect of treatment: $F_{1,176}=1.83, P=0.18$; effect of parental similarity: $F_{1,176}=0.27, P=0.18$; interaction between parental similarity and admixture treatment: $F_{1,175}=3.07, P=0.08$ ) (Fig. 3). However, for the microsatellite data, there was a significant effect of the interaction between admixture treatment and parental similarity $\left(F_{1,175}=4.31, P=0.04\right)$, reflecting that there was a positive relationship between similarity and hatching success for purebred families (a positive slope), whereas parental similarity was not associated with hatching success in the admixed families (Fig. 3).

When the data was further separated into specific population combinations ( 3 purebred and 3 admixed groups, based on the source population of each of the parental individuals) (Fig. 4), Student's T-tests showed that the association between parental similarity and hatching success differed among the purebred populations for the microsatellite dataset $\left(F_{1,2}=7.47, P<0.001\right)$, but not for the neutral SNP dataset $\left(F_{1,2}=0.72, P=0.49\right)$ whereas adaptive SNPs approached marginal significance $\left(F_{1,2}=2.81, P=\right.$ 0.061). No significant interaction effects between parental similarity and population combination were found for the admixed population combinations for any of the marker types (microsatellites: $F_{1,2}=0.95$, $P=0.3880$; neutral SNPs: $F_{1,2}=0.81, P=0.446$; adaptive SNPs: $F_{1,2}=1.73, P=0.177$ ).

\section{Discussion}

Increased knowledge about the effects of admixture can further the understanding about evolution of genetic structure and what shapes patterns of diversity, and also help avoid undesirable effects 
associated with conservation measures and management actions. In the present study, we used data for pike to evaluate whether estimates of parental genetic similarity based on three different marker types (microsatellites, neutral SNPs and adaptive SNPs) could predict the outcome of admixture. To our knowledge, this is the first attempt to systematically evaluate and compare the utility of different markers as proxies of parental compatibility and predictors of offspring performance. The main findings were that: $i$ ) estimated parental similarity differed between the marker types, and were consistently higher for purebred families compared to admixed families; ii) parental similarity was not consistently or clearly associated with hatching success for any of the marker types; and iii) the association between hatching success and parental similarity as estimated based on microsatellites was different for purebred and admixed groups, and also differed between population combinations.

\section{Parental similarity differed between marker types}

The findings that both values and ranges of estimated parental similarity differed between the marker types (Fig. 1) were expected, and likely reflect differences in the inherent properties of the marker types and datasets. The higher similarity estimates obtained for both of the SNP datasets (genome-wide neutral and adaptive) compared to microsatellites (neutral) is likely explained by the higher number of alleles per locus for microsatellites [26, 27], which might lead to overestimation of differentiation between individuals [26]. Moreover, the denser RADseq SNP data ( 1500 SNPs) is more likely to represent genome-wide diversity than the moderate number of microsatellites [28]. The wider range of similarity for both microsatellites and adaptive SNPs compared to neutral SNPs likely in part reflect the relatively low number of loci used for the former two, as each allele will have a large effect on the estimated similarity. In addition, the wide range for adaptive SNPs likely reflects in part that the adaptive dataset consists of a mixture of loci under diversifying and balancing selection. Taken together, this calls for caution when comparing results of studies that have used different markers, and comparisons should be based on ranking rather than absolute values.

The finding that purebred families had higher parental similarity than admixed families for all datasets (Fig. 1) was also expected as the three study populations are both neutrally and adaptively differentiated $[32,41,42]$. That similarity estimates were higher for neutral SNPs than for adaptive SNPs for admixed families but did not differ for purebred families, likely reflects differences in neutral and adaptive evolution. Neutral loci are only affected by neutral and stochastic processes, whereas functional loci are also affected by deterministic processes such as selection [30,43]. For admixed families, the loci in the adaptive dataset are probably under diversifying selection (as the algorithm used in the study identifies the outlier loci under diversifying selection [44]), which would explain the higher degree of differentiation observed for adaptive SNPs.

\section{No association between parental similarity and hatching success}

While there was no overall association between hatching success and parental similarity for any of the marker types (Fig. 2), the results indicated that the effect of parental similarity might differ between purebred and admixed families, and that the association was positive only for purebred families (Fig. 3). 
The large variation in hatching success for both admixed and purebred families throughout the similarity ranges for all marker types (Fig. 3) and the lack of any consistent association across marker types between parental similarity and offspring hatching success argues against the utility of parental genetic similarity estimates as a reliable predictive proxy for admixture effects in this system. It is possible that the range of genetic differentiation between the study populations was not wide enough to get a complete picture, that effects of admixture manifest more strongly in natural environments due to differences in the selective regimes [45-47], and that some admixture effects are not expressed until the F2 generation $[10,14,16]$. That our analyses, like some previous investigations of other species [17-20, $22,23,48]$, failed to detect any association between parental similarity and offspring performance cannot be taken as evidence that the genetic resemblance between parents is of no importance. However, that such an association apparently is difficult to detect is both disappointing and problematic, particularly from an applied conservation perspective.

Sadly, the conclusion that parental similarity is a poor predictor of the response to admixture extends to other candidate proxies, such as geographic distance, neutral genetic differentiation, genetic diversity or environmental similarity. Empirical studies using these different proxies $[3,11,14,16-18,29,49,50]$ show conflicting results. This inconsistency is likely reflective of the complex interactions between environmental factors and inherent properties of the parental populations $[15,50]$.

\section{Conclusions}

The present study showed that parental similarity was not consistently or clearly associated with hatching success for any of the marker types (neutral, genome-wide neutral, and adaptive). Our present study thus strengthens the conclusion that, as of today, there is no proxy that can reliably predict the outcome of admixture. There is therefore a clear need for further studies and different approaches to advance knowledge that can shed light on how to safeguard against negative consequences of admixture, and thereby inform management and promote successful conservation of biological diversity.

\section{Methods}

\section{Study species}

Pike is a long-lived fish that inhabits both freshwater and brackish water systems [51]. As one of the most common large predatory fishes in the Baltic Sea, it fills an important function in many systems where it regulates the abundance of species in lower trophic levels through top-down trophic cascades [52, 53]. As a valued species in both commercial and recreational fishing, pike is also socio-economically important $[37,54]$. It has also emerged as a model system for studies of ecology and evolution [55]. Unfortunately, pike populations in the Baltic Sea have been experiencing declines during the last decades $[37,38,53$, 56]. Several different factors, such as eutrophication, habitat loss, overfishing, and altered species interactions, have been proposed to have contributed to the decrease [37, 38, 53, 57, 58]. Due to the importance of pike, management actions, e.g., restoration of spawning locations (wetlands), and large- 
scale stocking programs have therefore been carried out to support and revitalize the populations $[39,40$, $59,60]$.

\section{Population localities}

The three populations of anadromous pike included in this study reproduce in different spawning habitats in the Kalmar Sound region [36]. Two of the localities (Lervik and Okne) are closely located in the

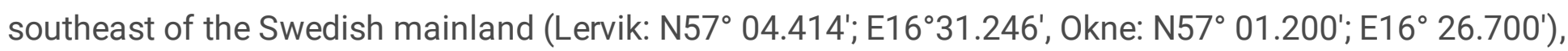
and the third locality (Harfjärden) is located on the east coast of the island of Öland (N56 $49.063^{\prime} ; \mathrm{E} 16^{\circ}$ $\left.48.673^{\prime}\right)$. All three populations are significantly genetically differentiated from each other as indicated by results from analyses based on both microsatellites [39, 41, 61] and RADseq SNPs [61, 2020d]. In addition, common garden and translocation experiments indicate that the study populations exhibit local adaptations for several traits including early life history traits and reproductive investment [63], salinity [36] and temperature tolerance [64], growth rate and adult body size [65] and vertebrae count [66].

\section{Estimates of hatching success}

We obtained estimates of hatching success from the study by Sunde, et al. [36] that investigated effects of admixture on F1 offspring performance [42]. In that study, gametes were collected from a total of 66 individuals from the three populations. To include the exact same set of individuals in both the hatching success dataset and genotyping dataset in the present study, we decided to omit two of the samples (that did not pass the quality control in the RADseq pipeline) before proceeding with the analyses (see the subsection Estimates of parental similarity below), thus resulting in a total of 64 parental individuals

(Harfjärden: $N_{\text {males }}=12, N_{\text {females }}=10$, Lervik: $N_{\text {males }}=12, N_{\text {females }}=9$, Okne: $N_{\text {males }}=10, N_{\text {females }}=11$ ). In short, separate batches of eggs from each female were artificially fertilized with milt from one male from each population (in total 180 units created from 90 female/male pairs (30 purebred and 60 admixed), each contributing duplicates). Eggs, and subsequently hatched fry were reared in a common garden environment, and three offspring performance measures (hatching success, survival during the first 15 days, and fry body length) were estimated (for details see [36]). Because hatching success was found to differ between treatments, we chose not to include the other offspring performance measures in the present study, to avoid using potentially biased estimates and low statistical power resulting from differences in hatching success, and the associated unequal and small sample sizes.

\section{Estimates of parental similarity}

We obtained estimates of parental genetic similarity from the study by Sunde, et al. [32], where the relative performance of the two marker types (microsatellites [67] and RADseq SNP data [68]) to detect genetic structure was evaluated in the study by Sunde, et al. [32], individuals were genotyped for ten microsatellite loci and 1580 SNPs. All ten microsatellites were found to be neutral, and the full RADseq dataset also reflected neutral evolution. In the present study we therefore used these datasets to represent partial neutral (microsatellites) and genome-wide neutral variation (the dataset referred to as 'neutral SNPs'). Sunde, et al. [32] further identified adaptive SNPs with multiple outlier analyses. In the present study we chose to use the 17 loci identified as outliers in the latent factor mixed model (LFMM) (for 
details see Table S1 in Additional file 1) analysis to represent adaptive variation (the dataset referred to as 'adaptive SNPs'). We used a more liberal approach for selecting adaptive SNPs than the original study to not exclude potential outliers, and to increase the number of included outlier loci (as compared to multiple testing). Based on the three datasets, we then estimated pairwise parental similarity as the proportion of alleles shared between individuals. This was calculated separately for each of the three datasets (microsatellites, neutral SNPs and adaptive SNPs) using R Studio v1.1.383 [69] with R v.3.2.2 [70].

\section{Statistical analysis}

General or generalized linear mixed models (depending on the distribution of response variables) were used to test whether and how parental similarity varied among the three marker types (microsatellites, neutral SNPs, and adaptive SNPs), whether hatching success was associated with parental similarity, and to explore whether and how associations between hatching success and parental similarity were affected by admixture treatment (differed between purebred and admixed families). For this, we used the Ime4 package v1.1-15 in RStudio with R. The different models were chosen based on the response distribution of the data: general linear mixed models for parental similarity (with a normal response distribution) and generalized linear mixed models with a logit-link function for hatching success (with a binomial response distribution).

For all tests, we treated marker type as a fixed categoric factor, parental similarity as a fixed continuous factor, and family (female/male pair) as a random factor. Statistical significance was assessed with Type III partitioning and an a-level of 0.05 , and the Satterthwaite's method was used to approximate degrees of freedom. For tests of interactions between factors, we excluded the interaction term and rerun the analysis in case of no significant interaction effect. For tests with significant terms, we further analyzed the data with Student's t-test with non-pooled SD or Tukey's test to determine the nature of the interactions and evaluate pairwise differences. P-values were adjusted using the FDR method [71] to account for multiple comparisons.

\section{Abbreviations}

FDR: False discovery rate

LFMM: Latent factor mixed model

PCA: Principal component analysis

RADseq: Restriction-site associated DNA sequencing

SD: Standard deviation

SNP: Single-nucleotide polymorphism 


\section{Declarations}

Ethics approval and consent to participate

Not applicable.

Consent for publication

Not applicable.

Availability of data and materials

The datasets supporting the conclusions of this article were obtained from previously pulished studies and are publicly available in Dryad Digital repository (Microsatellite genotype data: https://doi.org/10.5061/dryad.31zcrjdgv [67]; data on hatching success: file "offspring.xlsx", https://doi.org/10.5061/dryad.dd64hf3 [42]), and the NCBI Sequence Read Archive (RADseq gentype data: BioProject PRJNA579326, https://www.ncbi.nlm.nih.gov/sra/PRJNA586770 [68]).

Competing interests

The authors declare that they have no competing interests.

\section{Funding}

Funding was provided by the Linnaeus University (to A.F.), and The Swedish Research Council FORMAS (to A.F. grant Dnr. 2017-00346).

Authors' contributions

JS and AF conceived the study. JS and YY analyzed the data. JS, AF and YY contributed to interpreting the results. JS and YY drafted the first manuscript. All authors commented on and agreed to the final version of the manuscript.

Acknowledgements

We would like to thank our colleagues in the evolutionary ecology and fish ecology research groups for stimulating discussions and valuable input on this study

\section{References}

1. Lynch M: The genetic interpretation of inbreeding depression and outbreeding depression. Evolution 1991, 45(3):622-629.

2. Rius M, Darling JA: How important is intraspecific genetic admixture to the success of colonising populations? Trends Ecol Evol 2014, 29(4):233-242. 
3. Weeks AR, Sgro CM, Young AG, Frankham R, Mitchell NJ, Miller KA, Byrne M, Coates DJ, Eldridge $M D B$, Sunnucks $P$ et al: Assessing the benefits and risks of translocations in changing environments: a genetic perspective. Evol App/2011, 4(6):709-725.

4. Hughes J, Goudkamp K, Hurwood D, Hancock M, Bunn S: Translocation causes extinction of a local population of the freshwater shrimp Paratya australiensis. Conserv Biol 2003, 17(4):1007-1012.

5. Verhoeven KJ, Macel M, Wolfe LM, Biere A: Population admixture, biological invasions and the balance between local adaptation and inbreeding depression. Proc Biol Sci 2011, 278(1702):2-8.

6. Glover KA, Pertoldi C, Besnier F, Wennevik V, Kent M, Skaala Ø: Atlantic salmon populations invaded by farmed escapees: quantifying genetic introgression with a Bayesian approach and SNPs. In: BMC Genetics. vol. 14; $2013: 74$.

7. Forsman A, Wennersten L: Inter-individual variation promotes ecological success of populations and species: evidence from experimental and comparative studies. Ecography 2016, 39(7):630-648.

8. Forsman A: Effects of genotypic and phenotypic variation on establishment are important for conservation, invasion and infection biology. Proc Biol Sci 2014, 111(1):302-307.

9. Hamilton JA, Miller JM: Adaptive introgression as a resource for management and genetic conservation in a changing climate. Conserv Bio/ 2016, 30(1):33-41.

10. Frankham R: Genetic rescue of small inbred populations: meta-analysis reveals large and consistent benefits of gene flow. Mol Ecol 2015, 24(11):2610-2618.

11. Frankham R, Ballou JD, Eldridge MD, Lacy RC, Ralls K, Dudash MR, Fenster CB: Predicting the probability of outbreeding depression. Conserv Biol 2011, 25(3):465-475.

12. Edmands S, Timmerman CC: Modeling factors affecting the severity of outbreeding depression. Conserv Biol 2003, 17(3):883-892.

13. Whitlock R, Stewart GB, Goodman SJ, Piertney SB, Butlin RK, Pullin AS, Burke T: A systematic review of phenotypic responses to between-population outbreeding. In: Environ Evid. vol. 2; 2013: 13.

14. Edmands S: Between a rock and a hard place: evaluating the relative risks of inbreeding and outbreeding for conservation and management. Mol Ecol 2007, 16(3):463-475.

15. Todesco M, Pascual MA, Owens GL, Ostevik KL, Moyers BT, Hübner S, Heredia SM, Hahn MA, Caseys C, Bock DG et al: Hybridization and extinction. Evol App/ 2016, 9(7):892-908.

16. Edmands S: Heterosis and outbreeding depression in interpopulation crosses spanning a wide range of divergence. Evolution 1999, 53(6):1757-1768.

17. Edmands S: Does parental divergence predict reproductive compatibility? Trends Ecol Evol 2002, 17(11):520-527.

18. Raabová J, Münzbergová Z, Fischer M: Ecological rather than geographic or genetic distance affects local adaptation of the rare perennial herb, Aster amellus. Biol Conserv 2007, 139(3):348-357.

19. Willi Y, van Buskirk J: Genomic compatibility occurs over a wide range of parental genetic similarity in an outcrossing plant. Proc Biol Sci 2005, 272(1570):1333-1338. 
20. Amos W, Wilmer JW, Fullard K, Burg TM, Croxall JP, Bloch D, Coulson T: The influence of parental relatedness on reproductive success. Proc Biol Sci 2001, 268(1480):2021-2027.

21. Bean K, Amos W, Pomeroy PP, Twiss SD, Coulson TN, Boyd IL: Patterns of parental relatedness and pup survival in the grey seal (Halichoerus grypus). Mol Ecol 2004, 13(8):2365-2370.

22. Jolivet $C$, Rogge $M$, Degen B: Molecular and quantitative signatures of biparental inbreeding depression in the self-incompatible tree species Prunus avium. Heredity 2013, 110(5):439-448.

23. Phillips KP, Jorgensen TH, Jolliffe KG, Richardson DS: Evidence of opposing fitness effects of parental heterozygosity and relatedness in a critically endangered marine turtle? J Evol Biol 2017, 30(11):1953-1965.

24. Li YC, Korol AB, Fahima T, Nevo E: Microsatellites within genes: structure, function, and evolution. Molecular Biology and Evolution 2004, 21(6):991-1007.

25. Srivastava S, Avvaru AK, Sowpati DT, Mishra RK: Patterns of microsatellite distribution across eukaryotic genomes. In: BMC Genomics. vol. 20; 2019: 153.

26. Väli Ü, Einarsson A, Waits L, Ellegren H: To what extent do microsatellite markers reflect genome-wide genetic diversity in natural populations? Mol Ecol2008, 17(17):3808-3817.

27. Hodel RGJ, Chen S, Payton AC, McDaniel SF, Soltis P, Soltis DE: Adding loci improves phylogeographic resolution in red mangroves despite increased missing data: comparing microsatellites and RAD-Seq and investigating loci filtering. In: Sci Rep. vol. 7; 2017: 17598.

28. Lemopoulos A, Prokkola JM, Uusi-Heikkilä S, Vasemägi A, Huusko A, Hyvärinen P, Koljonen M-L, Koskiniemi J, Vainikka A: Comparing RADseq and microsatellites for estimating genetic diversity and relatedness - Implications for brown trout conservation. Ecol Evol 2019, 9(4):2106-2120.

29. Fenster CB, Galloway LF: Population differentiation in an annual legume: genetic architecture. Evolution 2000, 54(4):1157-1172.

30. Andrews KR, Good JM, Miller MR, Luikart G, Hohenlohe PA: Harnessing the power of RADseq for ecological and evolutionary genomics. Nat Rev Genet 2016, 17(2):81-92.

31. Santure AW, Stapley J, Ball AD, Birkhead TR, Burke T, Slate J: On the use of large marker panels to estimate inbreeding and relatedness: empirical and simulation studies of a pedigreed zebra finch population typed at 771 SNPS. Mol Ecol 2010, 19(7):1439-1451.

32. Sunde J, Yıldırım Y, Tibblin P, Forsman A: Comparing the performance of microsatellites and RADseq in population genetic studies: Analysis of data for pike (Esox lucius) and a synthesis of previous studies. In: Front Genet. vol. 11; 2020.

33. Forstmeier W, Schielzeth H, Mueller JC, Ellegren H, Kempenaers B: Heterozygosity-fitness correlations in zebra finches: microsatellite markers can be better than their reputation. Mol Ecol 2012, 21(13):3237-3249.

34. Charlesworth B, Charlesworth D: Population genetics from 1966 to 2016. Heredity 2017, 118:2-9.

35. McClelland EK, Naish KA: What is the fitness outcome of crossing unrelated fish populations? A meta-analysis and an evaluation of future research directions. Conserv Genet 2007, 8(2):397-416. 
36. Sunde J, Tibblin P, Larsson P, Forsman A: Sex-specific effects of outbreeding on offspring quality in pike (Esox lucius). Ecol Evol 2018, 8:10448-10459.

37. Lehtonen H, Leskinen E, Selen R, Reinikainen M: Potential reasons for the changes in the abundance of pike, Esox lucius, in the western Gulf of Finland, 1939-2007. Fisheries Management and Ecology 2009, 16(6):484-491.

38. Ljunggren L, Sandstrom A, Bergstrom U, Mattila J, Lappalainen A, Johansson G, Sundblad G, Casini M, Kaljuste O, Eriksson BK: Recruitment failure of coastal predatory fish in the Baltic Sea coincident with an offshore ecosystem regime shift. ICES Journal of Marine Science 2010, 67(8):1587-1595.

39. Larsson P, Tibblin P, Koch-Schmidt P, Engstedt O, Nilsson J, Nordahl O, Forsman A: Ecology, evolution, and management strategies of northern pike populations in the Baltic Sea. Ambio 2015, 44:451461.

40. Skov C, Nilsson PA: Evaluating stocking of YOY pike Esox lucius as a tool in the restoration of shallow lakes. Freshwater Biology 2007, 52(9):1834-1845.

41. Nordahl O, Koch-Schmidt P, Sunde J, Yıldırım Y, Tibblin P, Forsman A, Larsson P: Genetic differentiation between and within ecotypes of pike (Esox lucius) in the Baltic Sea. Aquat Conserv: Mar Freshwat Ecosyst 2019, 29:1923-1935.

42. Sunde J, Tibblin P, Larsson P, Forsman A: Data from: Sex-specific effects of outbreeding on offspring quality in pike (Esox lucius). In: The Dryad Digital Repository https://datadryad.org/stash: doi: 10.5061/dryad.dd64hf3; 2018.

43. de Villemereuil P, Gaggiotti OE: A new FST-based method to uncover local adaptation using environmental variables. Methods Ecol Evol 2015, 6(11):1248-1258.

44. Gain C, François O: LEA 3: Factor models in population genetics and ecological genomics with R. In: bioRxiv. 2020: 2020.2010.2006.327783.

45. Harshman LG, Hoffmann AA: Laboratory selection experiments using Drosophila: what do they really tell us? Trends Ecol Evol 2000, 15(1):32-36.

46. Ellegren H, Sheldon BC: Genetic basis of fitness differences in natural populations. Nature 2008, 452(7184):169-175.

47. Bicskei B, Taggart JB, Bron JE, Glover KA: Transcriptomic comparison of communally reared wild, domesticated and hybrid Atlantic salmon fry under stress and control conditions. BMC Genetics 2020, 21(1):57.

48. Lutz ML, Tonkin Z, Yen JDL, Johnson G, Ingram BA, Sharley J, Lyon J, Chapple DG, Sunnucks P, Pavlova A: Using multiple sources during reintroduction of a locally extinct population benefits survival and reproduction of an endangered freshwater fish. In: Evol Appl. vol. 00; 2020: 1-15.

49. Waser NM, Price MV, Shaw RG: Outbreeding depression varies among cohorts of Ipomopsis aggregata planted in nature. Evolution 2000, 54(2):485-491.

50. Rollinson N, Keith DM, Houde ALS, Debes PV, McBride MC, Hutchings JA: Risk assessment of inbreeding and outbreeding depression in a captive-breeding program. Conserv Biol 2014, 28(2):529-540. 
51. Craig JF: A short review of pike ecology. Hydrobiologia 2008, 601:5-16.

52. Donadi S, Austin ÅN, Bergström U, Eriksson BK, Hansen JP, Jacobson P, Sundblad G, van Regteren M, Eklöf JS: A cross-scale trophic cascade from large predatory fish to algae in coastal ecosystems. In: Proc R Soc B-Biol Sci. vol. 284; 2017: 20170045.

53. Nilsson J, Flink H, Tibblin P: Predator-prey role reversal may impair the recovery of declining pike populations. J Anim Ecol 2019, 88(6):927-939.

54. Pierce RB, Tomcko CM, Schupp DH: Exploitation of northern pike in seven small north-central Minnesota Lakes. North American Journal of Fisheries Management 1995, 15(3):601-609.

55. Forsman A, Tibblin P, Berggren H, Nordahl O, Koch-Schmidt P, Larsson P: Pike Esox lucius as an emerging model organism for studies in ecology and evolutionary biology: a review. Journal of Fish Biology 2015, 87(2):472-479.

56. Olsson J: Past and current trends of coastal predatory fish in the Baltic Sea with a focus on perch, pike, and pikeperch. In: Fishes. vol. 4; 2019: 7.

57. Laikre L, Miller LM, Palme A, Palm S, Kapuscinski AR, Thoresson G, Ryman N: Spatial genetic structure of northern pike (Esox lucius) in the Baltic Sea. Molecular Ecology 2005, 14(7):1955-1964.

58. Nilsson J: Predation of northern pike (Esox lucius L.) eggs: A possible cause of regionally poor recruitment in the Baltic Sea. Hydrobiologia 2006, 553:161-169.

59. Craig JF (ed.): Pike - biology and exploitation. London: Chapman \& Hall; 1996.

60. Larsen PF, Hansen MM, Nielsen EE, Jensen LF, Loeschcke V: Stocking impact and temporal stability of genetic composition in a brackish northern pike population (Esox lucius L.), assessed using microsatellite DNA analysis of historical and contemporary samples. Heredity 2005, 95(2):136-143.

61. Sunde J, Yıldırım Y, Tibblin P, Forsman A: Comparing the performance of microsatellites and radseq in population genetic studies: Analysis of data for pike (Esox lucius) and a synthesis of previous studies. In: Frontiers in Genetics. vol. 11; 2020.

62. Sunde J, Yıldırım Y, Tibblin P, Bekkevold D, Skov C, Nordahl O, Larsson P, Forsman A: Neutral and adaptive differentiation in pike (Esox lucius) populations from contrasting environments. In: Authorea Preprints. 2020.

63. Berggren $\mathrm{H}$, Nordahl O, Tibblin P, Larsson P, Forsman A: Testing for local adaptation to spawning habitat in sympatric subpopulations of pike by reciprocal translocation of embryos. In: PLOS ONE. vol. 11; 2016.

64. Sunde J, Larsson P, Forsman A: Adaptations of early development to local spawning temperature in anadromous populations of pike (Esox lucius). In: BMC Evol Biol. vol. 19; 2019: 1-13.

65. Tibblin P, Forsman A, Koch-Schmidt P, Nordahl O, Johannessen P, Nilsson J, Larsson P: Evolutionary divergence of adult body size and juvenile growth in sympatric subpopulations of a top predator in aquatic ecosystems. The American Naturalist 2015, 186(1):98-110.

66. Tibblin P, Forsman A, Borger T, Larsson P: Causes and consequences of repeatability, flexibility and individual fine-tuning of migratory timing in pike. The Journal of Animal Ecology 2016, 85(1):136- 
145.

67. Sunde J, Yildirim Y, Tibblin P, Forsman A: Data from: Comparing the performance of microsatellites and RADseq in population genetic studies: analysis of data for pike (Esox lucius) and a synthesis of previous studies. In: The Dryad Digital Repository. doi: 10.5061/dryad.31zcrjdgv; 2020.

68. Sunde J, Yildirim Y, Tibblin P, Forsman A: Data from: Comparing the performance of microsatellites and RADseq in population genetic studies: analysis of data for pike (Esox lucius) and a synthesis of previous studies. In: NCBI Sequence Read Archive. https://www.ncbi.nlm.nih.gov/sra/PRJNA586770; 2020.

69. RStudio Team: RStudio: Integrated development for R. In., 1.1.838 edn. Boston, MA: RStudio, PBC; 2017.

70. R Core Team: R: A language and environment for statistical computing. R Foundation for Statistical Computing. In. Vienna, Austria; 2015.

71. Benjamini Y, Hochberg Y: Controlling the false discovery rate - a practical and powerful approach to multiple testing. J R Stat Soc B 1995, 57(1):289-300.

\section{Figures}
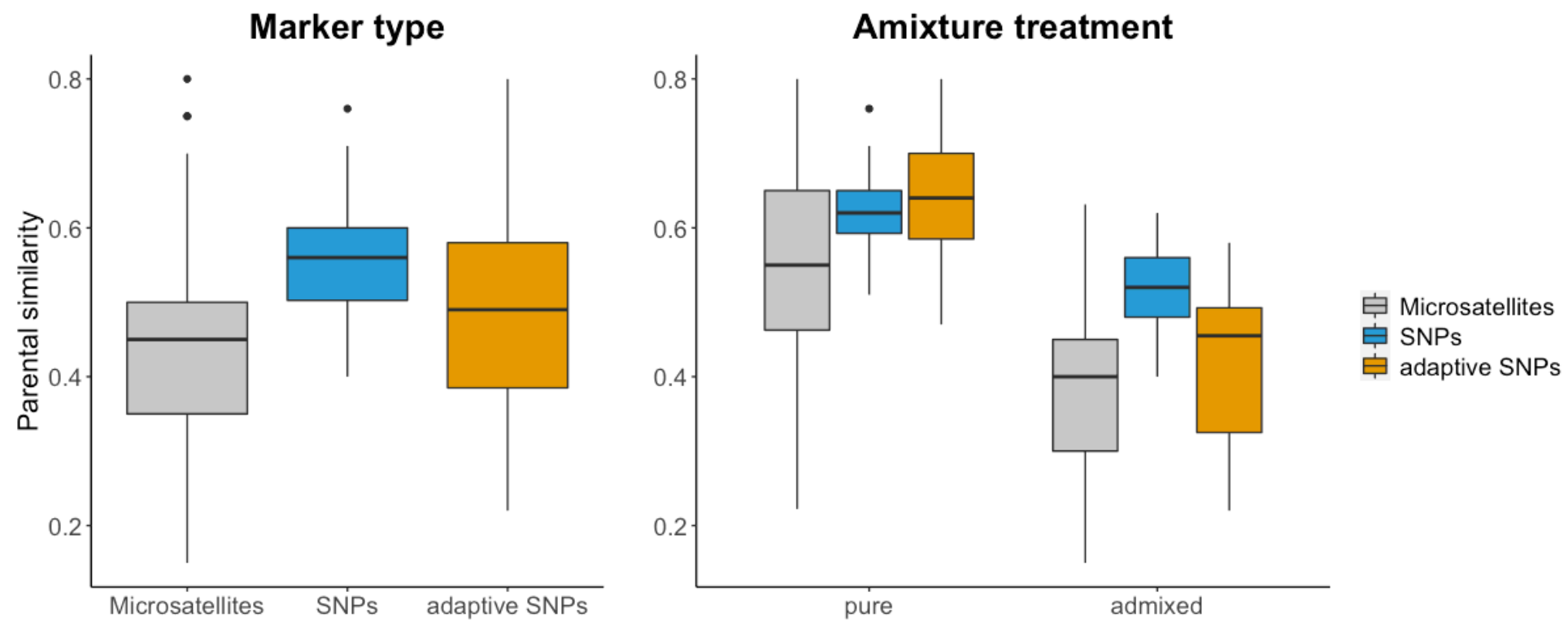

\section{Figure 1}

Estimates of pairwise parental similarity (proportion of alleles shared between individuals) for the same set of individuals $(\mathrm{N}=64)$. Estimates are based on three different datasets: neutral (microsatellites), genome-wide neutral (RADseq SNPs), and adaptive (outlier RADseq SNPs under selection). Left panel show estimates for all families, and the right panel show estimates for the two admixture treatments (purebred and admixed) separated. 

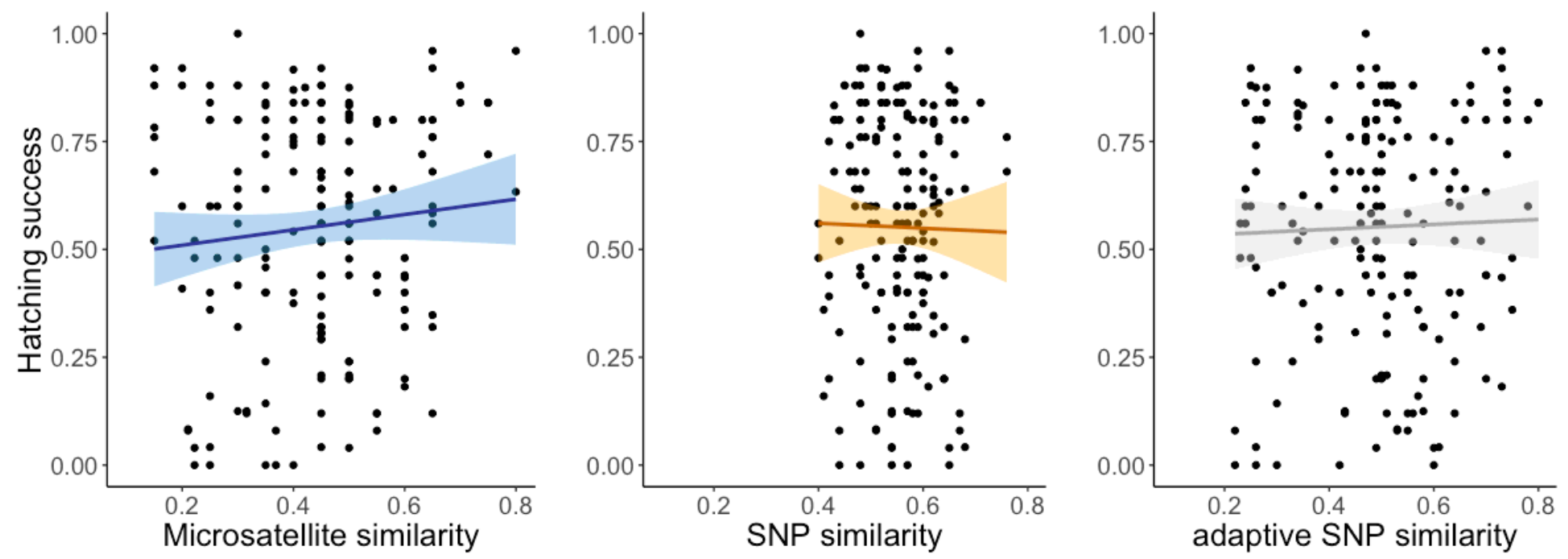

Figure 2

Relationship between hatching success and pairwise parental similarity estimated based on the three different datasets: microsatellites (left plot), RADseq SNPs (middle plot), and adaptive (outlier) RADseq SNPs (right plot).
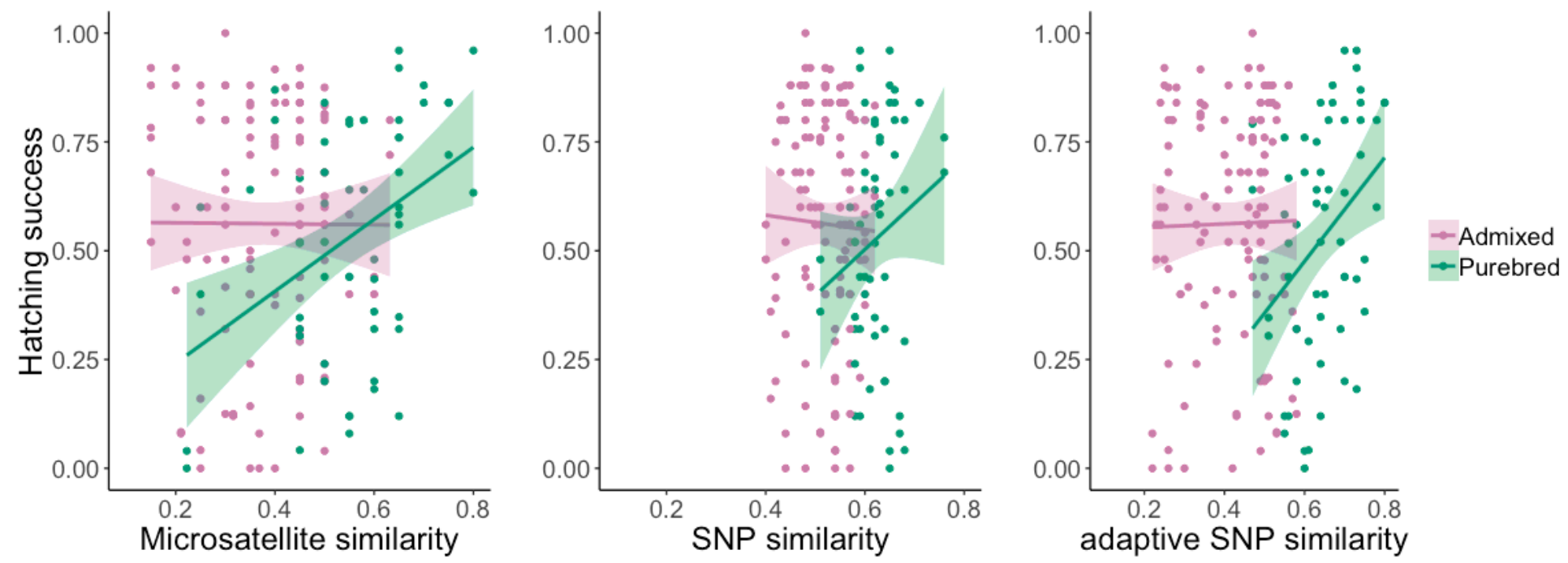

Figure 3

Relationship of purebred (green) and admixed (purple) families between hatching success and pairwise parental similarity estimated based on three different datasets: microsatellites (left plot), RADseq SNPs (middle plot), and adaptive (outlier) RADseq SNPs (right plot). 

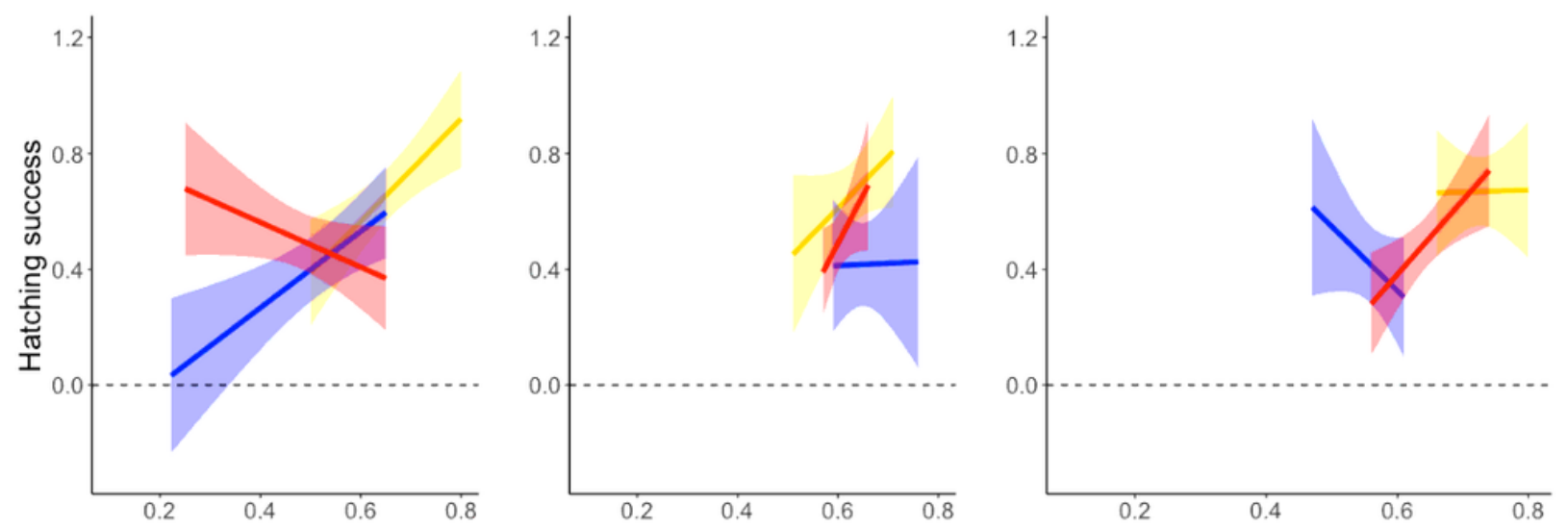

Population combination

- Harfjärden pure

- Lervik pure

- Okne pure
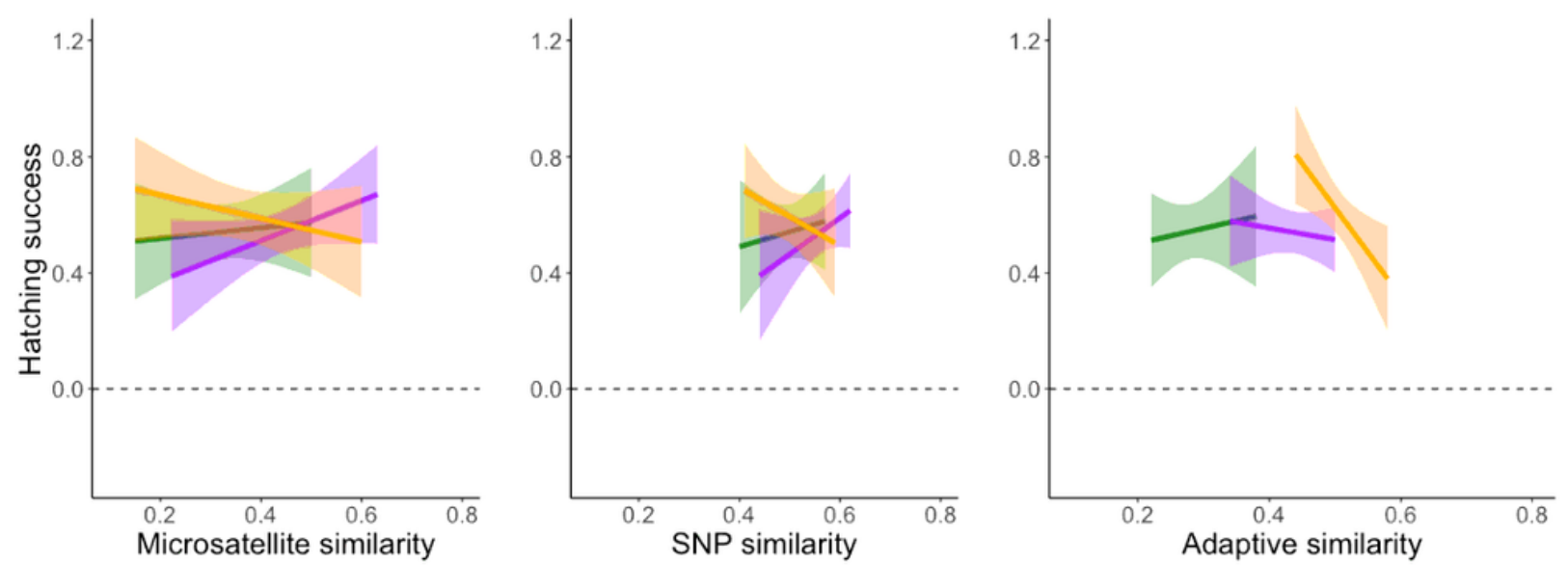

Population combination

- Harfjärden - Lervik

Lervik - Okne

Okne - Harfjärden

Figure 4

Relationship between hatching success and pairwise parental similarity estimated based on microsatellites (left column), RADseq SNPs (middle column), and adaptive (outlier) RADseq SNPs (right column) for purebred (top row) and admixed (bottom row) population combinations: based on three different datasets.

\section{Supplementary Files}

This is a list of supplementary files associated with this preprint. Click to download.

- Additionalfile1.docx 